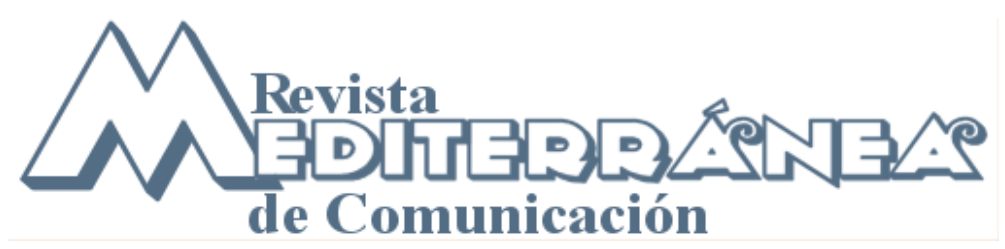

Año 3 (2012), pp. 59-78 ISSN 1989-872X

\title{
El tratamiento fotoperiodístico tras la victoria de la Selección Española de Fútbol en el Mundial de Sudáfrica 2010
}

\section{The photojournalistic treatment after Spanish Soccer Team's Victory in World Cup South Africa 2010}

\author{
DEA Belén Puebla Martínez, y \\ Universidad Rey Juan Carlos - España \\ belen.puebla@urjc.es \\ DEA Elena Carrillo Pascual \\ Universidad Rey Juan Carlos - España \\ DEA Ana Isabel Iñigo Jurado \\ Universidad Rey Juan Carlos - España
}

\section{Resumen}

Este estudio analiza el tratamiento fotográfico dado a la victoria de la Selección Española de Fútbol en el Mundial de 2010 en la prensa generalista española. Para ello, se han considerado las imágenes aparecidas en los tres periódicos de mayor tirada nacional en su edición madrileña: El País, El Mundo y Abc, en los tres días posteriores a la final de Mundial: 12, 13 y 14 de julio de 2010. De esta manera, se ha comprobado la frecuencia de aparición de fotografías sobre dicho acontecimiento. Además, se han analizado las principales características de las imágenes así como las funciones representativas y el valor simbólico de éstas, destacando el protagonismo de la bandera y el color rojo como señas de identidad de este acontecimiento mediático.

\section{Abstract}

This study analyzes the photographic treatment given to the victory of the Spanish National Team in the 2010 World Cup in the Spanish general press. For that, the images appeared in the Madrilenian edition of the three main newspapers -'El País', 'El Mundo' and 'ABC'- have been considered. By this method, the frequency of the presence of these images about this event has been checked. In addition, the main characteristics of those images, and their representative functions, as well as their 
symbolic value, have been analyze, emphasizing on the leading role of the flag and colour red as identity signs of this mediatic event.

Palabras claves

Selección Española de Fútbol; fotografías; color; prensa; rojo; Mundial de Fútbol Sudáfrica 2010.

Key Words

Spanish Soccer Team; photographies; colour; red; Southafrica World Cup 2010.

Sumario: 1. Introducción; 2. Metodología; 3. Resultados; 3.1. Análisis del ejemplar; 3.2. Análisis de los elementos gráficos; 3.3. Espacio y tiempo en el que se desarrolla la acción; 3.4. Análisis cualitativo; 4. Conclusiones; 5. Bibliografía.

Summary: 1. Introduction; 2. Methodology; 3. Results; 3.1. Example analysis; 3.2. Graphic elements analysis; 3.3. Space and time where the action is in; 3.4. Qualitative Analysis; 4. Conclusions; 5. Bibliography.

\section{Introducción}

Por primera vez en la historia, el 11 de julio de 2010, España se proclamó campeona del mundo de fútbol en Sudáfrica. Un hecho tan importante, en el que por primera vez en la historia la Selección Española consigue la copa del mundo, no ha pasado desapercibido para los medios. Televisiones, radios y prensa se hicieron eco del acontecimiento. Esta victoria hizo que España entera saliera a la calle a celebrarlo. Por un lado, la celebración de los jugadores en el campo, seguidamente el encuentro con la afición por las calles de Madrid y, por último, el recibimiento por las diferentes autoridades a los ganadores. Un seguimiento cronológico que han recogido los medios hasta la saciedad. Los días 12, 13 y 14 de julio España se convirtió en una fiesta donde los protagonistas fueron la Selección de fútbol, los aficionados y, por supuesto, la bandera española.

En el plano internacional acontecimientos de la relevancia de los Juegos Olímpicos o la Copa del Mundo de Fútbol se convierten en eventos con una gran notabilidad social porque como afirma Dunning (1992: 266): "1) el hecho de que se ha convertido en una de las principales fuentes de emoción agradable; 2 ) el hecho de que se ha convertido en uno de los principales medios de identificación colectiva; 3) el hecho de que ha llegado a constituirse en una de las claves que dan sentido a las vidas de muchas personas".

Si por norma, el tiempo dedicado en televisión o el espacio destinado a deportes en prensa es muy amplio, si hablamos de fútbol y del triunfo de la Selección la importancia se dispara, ya que es el deporte más seguido por el público. Para González Ramallal:

"El fútbol es el lugar común de toda la prensa española. La jerarquía de acontecimientos deportivos, de modalidades deportivas, de actores protagonistas, de actores mencionados, de imágenes y gráficos reflejados en la prensa, y de unidades de información deportiva [...] responden invariablemente, y sin apenas distinción por diario, a un esquema gobernado 'autoritariamente' por el fútbol, que se conforma así, como el prototipo de deporte mediático por excelencia." (González Ramallal, 2004: 281). 


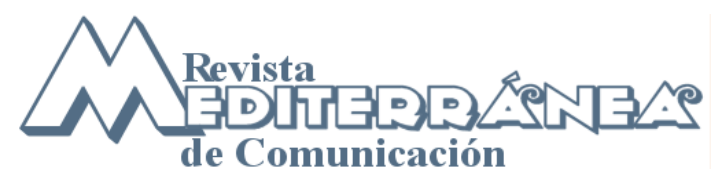

ISSN 1989-872X - Año3 (2012), pp. 59-78

En esta investigación pretendemos comprobar la representación visual de la victoria de la Selección Española en el Mundial de Fútbol de Sudáfrica 2010, el tratamiento fotográfico que se le ha dado a dicha celebración en la prensa diaria generalista española, centrándonos en los tres periódicos de mayor tirada: El País, El Mundo y Abc.

La fotografía es sin duda un elemento de gran importancia en los periódicos. Sea en un diario, sea en una revista, las imágenes cumplen un decisivo papel en la construcción del sentido global de noticias y ofrecen, junto a los textos, un conjunto de significados para los hechos de los cuales se informa. En este escenario se puede afirmar la necesaria complementariedad que debe haber entre discursos visuales y verbales. Aun así, la imagen puede recoger toda la información sin necesidad de un texto que le acompañe ya que como afirma Vilches (1993: 71) "La foto de prensa como texto icónico autónomo puede ser visible y legible, adecuado y comprensible sin necesidad de una 'leyenda' o texto escrito que le acompañe".

Las fotografías analizadas ayudan a dar sentido a los textos sobre la victoria de La Roja y, al mismo tiempo, desde el punto de vista de la investigación, construyen una narrativa específica sobre este acontecimiento. De esta forma, resulta interesante investigar cómo los diarios de referencia han realizado el tratamiento visual sobre un hecho nacional histórico. Como apunta Alonso Erausquin (1995: 105) "la lectura del texto icónico debe relacionarse con su entorno físico real, con sus condiciones productivas y con la recepción, que lo contextualiza".

El diseño de estas páginas tanto en la parte textual como en la icónica intenta ser lo más llamativo posible ya que como señala Paniagua Santamaría (2010: 184) "Esta especialización del lenguaje [tanto visual como textual] le aporta a la información deportiva viveza, emoción, colorido, aspectos muy variados relacionados con el juego". Estamos hablando de un diseño que quiere acercarse al lenguaje audiovisual al que los lectores están muy habituados. Para Berrocal y Rodríguez (1998: 64) "el diseño ayuda a competir con la televisión de modo que el periódico sea más atractivo". Como veremos más adelante hay imágenes en las que parece poder apreciarse los sonidos del momento que recoge la instantánea.

El objetivo principal de esta investigación es comprobar cuantitativa y cualitativamente la presencia y el tratamiento de las fotografías sobre la Selección Española y sus celebraciones después de la consecución de la Copa del Mundo de Fútbol. Para ello, nos centraremos en descubrir los siguientes objetivos particulares:

1. Comprobar si los diarios utilizan un diseño exclusivo con motivo de la victoria de la Selección Española de Fútbol.

2. Analizar la composición y la distribución de los elementos de las imágenes.

3. Interpretar el contenido de las imágenes, atendiendo principalmente su vertiente connotativa.

4. Buscar la intencionalidad del medio al seleccionar ciertas imágenes.

5. Identificar el uso de símbolos como la bandera o la copa. 


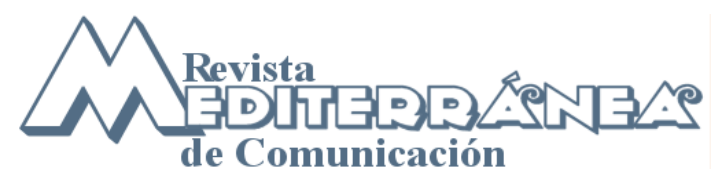

ISSN 1989-872X - Año3 (2012), pp. 59-78

Vivimos en un mundo predominantemente visual en el que la imagen cumple una función primordial a la hora de comunicar y transmitir representaciones de la realidad de la que formamos parte. En este sentido, aunque el concepto de imagen se aplica a gran número de fenómenos, debemos entender ésta como representaciones o alusiones de una realidad externa a la propia realidad o esencia de la imagen (Erausquin, 1995: 20). Como afirma García Maza (2005: 262) "la cultura dominada por el lenguaje se ha desplazado hacia lo icónico para acelerar el proceso de comunicación [...] y la gran cantidad de imágenes que bombardean nuestros sentidos cada día, gracias a las nuevas tecnologías de lo visual, demandan una nueva forma de leer y escribir". Es por ello que cada individuo interpreta cada representación visual según su propia experiencia y de acuerdo a su forma de entender el mundo que le rodea.

En este sentido Viches (1993: 14) afirma que el fotoperiodismo es, en el ámbito de la comunicación, además de una actividad artística un elemento esencial de información y opinión. García Maza (2005: 263) pone además el acento en la relación entre la realidad y la fotografía de prensa y afirma que "en el fotoperiodismo se manifiestan las relaciones que se establecen entre las fotografías y los hechos de actualidad [...] La imagen fotoperiodística tiene como función más alta la de aportar testimonios, movilizar conciencias y transformar la realidad". Así, es capaz de ofrecer pruebas a la sociedad para corregir todo lo que la daña, aunque a veces la imagen de prensa puede responder a intereses de distinto índole por lo que puede descontextualizar y modificar la realidad hasta engañar al lector. Por esta razón, aunque la imagen, y más en concreto la fotografía, se haya asociado tradicionalmente a la idea de transparencia debemos tener presente que no es así.

La fotografía no debe entenderse sólo como un testigo fiel del acontecimiento que transmite, sino como un espejo de esta realidad que es representada con una intencionalidad decidida a priori. La imagen representa un mensaje que ha sido seleccionado, valorado y tratado por un determinado medio que ha querido presentarnos un hecho de una determinada forma, por ello, las imágenes no deben entenderse como fiel reproducciones de su original. En palabras de Teixeira Ribeiro (1998: web), el objetivo de la imagen es "transmitir una información de asimilación instantánea, pues en su proceso de lectura hay un amplio y directo desencadenamiento de las reacciones emocionales". En este sentido, podemos afirmar que "La fotografía de prensa representa en la actualidad un destacado modo de expresión dentro de la comunicación profesional" (Torregrosa, 2009: 27).

En el caso de la fotografía periodística debemos retomar las palabras de Alonso Erausquin (1995: 8) quien afirma que la función principal del fotoperiodismo es la de mediar entre un observador de acontecimientos de actualidad y un receptor que acepta observar esa realidad indirectamente. Pero la función del fotoperiodismo va más allá del simple instrumento informante de actualidad y puede también realizar otras funciones dentro del plano comunicativo, por ejemplo, la función documental o ilustrativa. Aun así, es importante poner el acento en el hecho de que aunque el fotoperiodismo puede tener distintos objetivos, este siempre se engloba en su función principal que es la de informar sobre algo.

La fotografía de prensa debe entenderse como un elemento más de comunicación y otorgarle la categoría que ello implica. Por ejemplo, como señala Vilches (1993: 77) en ningún caso la foto de prensa debe entenderse como un elemento más simple que el propio texto al que acompaña ya que en numerosas ocasiones puede presentarse como un elemento autónomo con sentido propio. Además, la foto tampoco debe concebirse como una ilustración del texto, sino como un elemento discursivo con capacidad para impactar sobre el receptor debido a las elaboraciones simbólicas de las que se compone. Así, "la foto de 
prensa se revela particularmente eficaz en ciertos procesos de reconocimiento e identificación" (Vilches, 1993: 77) sin olvidar la función práctica del texto escrito. De esta forma, ambos elementos -texto e imagen- se convierten en textuales y sirven para apoyar ciertos procesos cognitivos del receptor.

Estamos por tanto ante un elemento - la foto de prensa - cuyo contendido no es evidente sino latente y debe interpretarse a "través de unidades culturales que están fuera de la imagen incluso del periódico y que pertenece al contexto o visión del mundo (conocimiento, memoria, escala e valores, rol social desempeñado, etc.)" (Vilches, 1993: 19). Para ello, la fotografía usa distintos elementos para transmitir la realidad según le convenga, a la vez que sirven de guía para reconocer los significados que nos quiere transmitir la fotografía. Estos elementos son los que se califican como componentes materiales de la imagen, aunque algunos autores, como Villafañe (1985: 97) los denomina elementos morfológicos de la imagen. Estos elementos harían referencia a:

El punto. Referido al elemento básico de la imagen que se caracteriza por su capacidad de actividad plástica, es decir, puede dar dinamismo a la imagen o constituir una representación por sí mismo.

La línea. Es el elemento principal de la escritura y otros sistemas de signos.

Entre sus funciones está la de dar volumen, separar planos, dar sensación de profundidad o generar formas.

La forma. Es una superficie de dimensión apreciable cuya existencia depende de otros elementos.

El plano. Es una forma que propone la ordenación del espacio en superficies articuladas y/o en niveles de profundidad.

La textura. Patrón visual formado por un conjunto de formas iguales o semejantes que se repiten según una pauta determinada de agrupación y que se extiende sobre un espacio bidimensional.

El color. Experiencia visual de la luz reflejada por un objeto. Se define por su tono, saturación y luminosidad.

Pero en términos de contenido informativo, además de estos elementos debemos de tener presente el esquema que propone Alonso Erausquin (1995: 105-175) para comprender las fotografías utilizadas en prensa con fines informativos. Para entender el sentido total de la imagen debemos distinguir entre siete modos de codificación que nos permitirán explorar las imágenes y acercarnos a su lectura:

Código espacial. Sobre este elemento debemos plantearnos dos cuestiones: primero, si la relación espacio incluido - espacio excluido puede modificar la información del acontecimiento reflejado y, segundo, si la amplitud del campo transmite significado por sí misma. Esta segunda cuestión está determinada por la elección de planos utilizados (plano general, planos intermedios, planos medios, primer plano, fragmentos del primer plano 0 elección de multitud de tomas formando una composición).

Código gestual. En este sentido se agrupan todos aquellos elementos relacionados con la comunicación no verbal, es decir, gestos y formas de expresión así como la proxémica, es 
decir, la ocupación territorial de los elementos representados. Alonso Erausquin (1995: 121) destaca en este sentido que "el gesto puede ser un símbolo intencional, puede venir a subrayar y acompañar la expresión verbal como adjetivación, o puede revelar, por sí mismo y con independencia incluso de la voluntad de su agente, un estado de ánimo o una actitud concreta".

Código escenográfico. Hace referencia al tipo de escena, atrezzo o ambiente, por lo que su función puede englobar aspectos tan diversos como, determinar la importancia del acontecimiento y situación de los mismos, conocer la localización geográfica y temporal de los hechos, condiciones climatológicas, identificación de los personajes con otros colectivos, calificación de los protagonistas según si indumentaria...

Código lumínico. Referido al uso de la luz y los colores. Según Alonso Erausquin (1995: 141) "los colores y no colores tiene en cada cultura un valor primordial incorporado [...] al ocuparnos de la fotografía de prensa, nos interesa destacar la importancia de la iluminación para la gradación de la gama de grises". La luz nos permite dar contraste a los diversos elementos representados y apreciar su relieve, profundidad o textura.

Código simbólico. Nos permite apreciar las particularidades de una imagen, asociando ésta a unos valores determinados. Para ello es necesario que el signo establezca una relación significativa con una realidad distinta.

Código gráfico. Compuesto por el "conjunto de factores significativos que resultan de la interacción entre los diferentes elementos materiales que constituyen la realidad física de la imagen" (1995: 154). Es decir, hablaríamos del material de soporte y las gamas de colores utilizadas, así como las técnicas y la tecnología empleada.

Código compositivo y de relación. Referido a la relación entre los diferentes elementos representados y vinculados entre si y que compondrían la interacción entre codificaciones y significación.

Podemos afirmar así, que la fotografía de prensa ha de ser entendida siempre desde su función comunicativa prestando atención a cada de uno de sus elementos tanto de forma aislada, analizando cada una de las funciones que cumple cada elemento que compone la imagen, como de manera global, para comprender el sentido total de la imagen representada. Los códigos fotográficos están por tanto relacionados con todo el proceso de mediación técnica que la fotografía requiere y que debemos conocer para comprender la imagen representada.

Por último, es importante hablar sobre la importancia del lenguaje visual en la redacción periodística del deporte, tema en el que nos centramos en este trabajo. En este sentido, y siguiendo las palabras de Castañón y Castañón (2006: 5) el lenguaje visual en el área deportiva fue impulsado tras los Juegos Olímpicos de 1992 celebrados en nuestro país. A partir de esa fecha, se puso en funcionamiento un lenguaje visual mucho más atractivo y directo para el receptor, gracias a los cambios en el formato y estructura de los medios usados. Se fomentó la espectacularidad y el colorido, sin renunciar a la veracidad, por lo que se logró proporcionar una gran fuerza expresiva tanto a los deportes representados en las fotografías de prensa, como a los protagonistas de las hazañas deportivas. En este sentido, el presente trabajo cobra especial importancia debido a dos hechos: por un lado la relevancia de los espectáculos deportivos en nuestro país, especialmente de las 


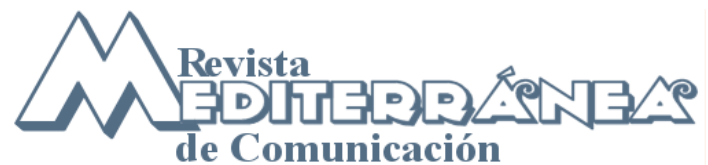

competiciones deportivas, y por otro, la figura de la fotografía en prensa como elemento potenciador de esta espectacularización de los encuentros deportivos de masas.

Es por esto que el deporte, y especialmente el fútbol, puede ser entendido como una representación de algo, como afirma González Ramallal (2003: 191) al destacar su puesta en escena y su teatralidad, es decir, su carácter dramatúrgico. En este sentido, el fútbol moderno se ha convertido en un fenómeno social a nivel prácticamente mundial debido sobre todo al gran número de personas que moviliza y a su dimensión lúdica y recreativa. En el caso de España, este hecho también se vio originado por causas diversas: "el número de competiciones y partidos que se celebran; por el número de jugadores y equipos que existen; por las cantidades de dinero que se manejan en concepto de traspasos, publicidad, fichas, primas, etc.; por el número de partidos que se televisan y por el tiempo que se le dedica en los medios; y, finalmente, por el número de telespectadores" (González Ramallal, 2004: 201). Además, en España surgió el concepto de 'furia española', una idea que identificó y sigue identificando a los jugadores de La Roja, los cuales, aunque en numerosas ocasiones fueron tachados de carecer de técnica, ésta era suplida por su garra y su coraje, que los hacía diferentes a los demás dentro del terreno de juego.

Debido a la importancia del fútbol como espectáculo, los medios de comunicación pasaron de tener una cobertura limitada a unos espacios y tiempo reducidos, a tener una cobertura incrementada como nunca antes se había visto. De hecho, la buena sintonía entre este deporte y los medios de comunicación, ayudaron a la espectacularización del fútbol en nuestro país. En este sentido la prensa jugó un papel determinante ya que como señalan Esteve y Fernández del Moral (1998: 275) "el deporte es una de las actividades que ocupa mayor espacio de todos los medios de comunicación y suscita mayores intereses entre los receptores".

En el caso de la prensa deportiva española, a partir de los años ochenta, se generalizó el uso del color en los gráficos e imágenes, algo que como afirma González Ramallal (2004: 266) se sigue manteniendo "ya que el color como recurso informativo que se plasma en las imágenes que aparecen en la prensa específicamente deportiva, refuerza las sensaciones y las emociones inherentes a la actividad deportiva". Aun así, en los diarios generalistas, objeto de estudio que aquí hemos analizado, la tendencia ha sido menos pronunciada.

Además, dentro de la jerarquía de noticias deportivas, los diarios españoles están condicionados por la temática del fútbol. Y en éstas, son las fotografías los elementos visuales más utilizados como forma de ilustrar la información deportiva.

\section{Metodología}

Nuestro estudio recoge la totalidad de las imágenes publicadas tras la victoria de la Selección Española en el Mundial de Fútbol de Sudáfrica de 2010. Seleccionamos los tres diarios de información generalista de mayor difusión de nuestro país: El País, El Mundo y Abc; y recopilamos los números pertenecientes a los tres días siguientes a la victoria, 12, 13 y 14 de julio de 2010, en su edición madrileña. Se eligieron los días en que la información del triunfo de la Selección aparecía en portada en los tres periódicos. De los nueve ejemplares, hemos encontrado un total de 468 elementos gráficos relacionados con la Selección. De ellos, 302 son fotografías, 82 son fotonoticias, 50 son viñetas y 34 son gráficos o infografías. 


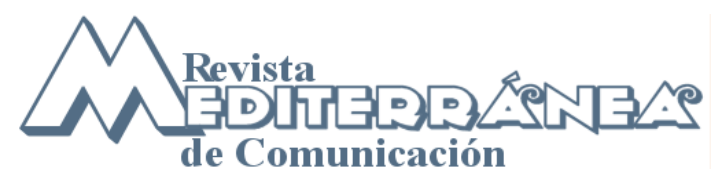

ISSN 1989-872X - Año3 (2012), pp. 59-78

Para el análisis de las imágenes utilizamos una ficha de análisis compuesta por 49 variables repartidas de la siguiente manera. En primer lugar, realizamos un análisis del diseño y de la distribución de las imágenes dentro de los ejemplares de esos tres días, mediante 13 variables. Por otro, estudiamos las características formales, técnicas y el contenido, analizando 36 variables, de las 302 fotografías y las 82 fotonoticias, lo que suponen 384 imágenes. Con este análisis pretendemos recoger un primer nivel de lectura de la imagen, su plano denotativo, lo que se ve en la fotografía.

El código de análisis se ha creado en base a la recopilación de los trabajos de autores como Barthes (1990), Alonso Erausquin (1995), Aparici y García Matilla (1998) o Baeza (2001).

La codificación de las 384 imágenes se realizó por un equipo formado por tres personas que se encargaron del vaciado de la prensa y de la codificación de todas las unidades de análisis. Para realizar la fiabilidad hemos utilizado el índice Alpha de Krippendorff, donde el valor mínimo de acuerdo es de 0,75. "La fiabilidad intercodificadores (intercoder reliability) mide el grado de consenso o acuerdo alcanzado entre los diferentes codificadores que, de forma separada, han analizado un mismo material con el mismo instrumento de codificación" (Igartúa y Humanes, 2004: 89). El porcentaje de acuerdo medio de las 49 variables analizadas fue de 0,89 , por tanto se cumplen los criterios que se pueden considerar adecuados superando en todas las variables acuerdos superiores al 0,7 (Wimmer y Dominick, 1996).

En segundo lugar, hemos realizado un análisis cualitativo con el fin de estudiar un segundo nivel de lectura de las imágenes en la que nos centramos en su plano connotativo. Como afirma Vilches (1993: 84) "el contenido en una foto de prensa no es nunca explícito sino latente, no es tampoco visual ni evidente sino conceptual y problemático. El contenido de una foto de prensa tampoco es obvio sino que se interpreta a través de unidades culturales que están fuera de la imagen e incluso del periódico y que pertenecen al contexto o visión del mundo (conocimiento, memoria, escala de valores, rol social desempeñado, etc.)".

La foto en prensa se presenta como una enciclopedia donde los lectores diversos pueden buscar diferentes significados según sus intereses. Por tanto con este análisis buscamos la interpretación de las fotografías desde variadas perspectivas. Para ello, se han clasificado las imágenes en cinco temáticas: la Selección como protagonista; los futbolistas retratados individualmente; la Selección acompañada de personajes públicos de diferentes ámbitos; los aficionados, tanto individualmente como masa humana; y por último; el protagonismo de símbolos como la copa, la bandera o los espacios emblemáticos donde se desarrolla la acción. Como se podrá comprobar no son temáticas excluyentes ya que en numerosas ocasiones vemos que se mezclan las temáticas en una misma fotografía.

Para la elaboración de este análisis se han tomado como base los modelos de estudio de contenido de la fotografía en prensa de autores como Vilches (1987), Abreu (2004), Rodríguez Merchán (1993) y, nuevamente, Alonso Erausquin (1995) del que se toman como referencia los siete códigos de codificación comentados anteriormente.

\section{Resultados}

Para llevar a cabo el análisis de resultados, primero nos centraremos en un análisis preliminar del ejemplar en que nos fijaremos en aspectos como el número de páginas dedicadas a la victoria de la Selección en cada periódico, el tipo de elementos gráficos usado o la existencia de un diseño especial en el ejemplar con motivo del acontecimiento 
analizado. Posteriormente, llevaremos a cabo un análisis centrado en los elementos gráficos seleccionados para conocer aspectos tales como el diseño y la composición de las imágenes, o el uso de elementos simbólicos en éstas.

\subsection{Análisis del ejemplar}

En primer lugar, nos hemos centrado en clasificar los 468 elementos gráficos relacionados con la Selección Española de Fútbol publicados en los nueve ejemplares analizados. Así, del total de elementos encontrados (468) debemos destacar que el $64,5 \%$ (302) son fotografías; el 17,5\% (82), fotonoticias, es decir fotografías que sin estar acompañadas de información tiene validez informativa por sí mismas; el 10,8\% (50) son viñetas y el 7,2\% (34) son gráficos o infografías.

Gráfico 1: tipo de elemento gráfico

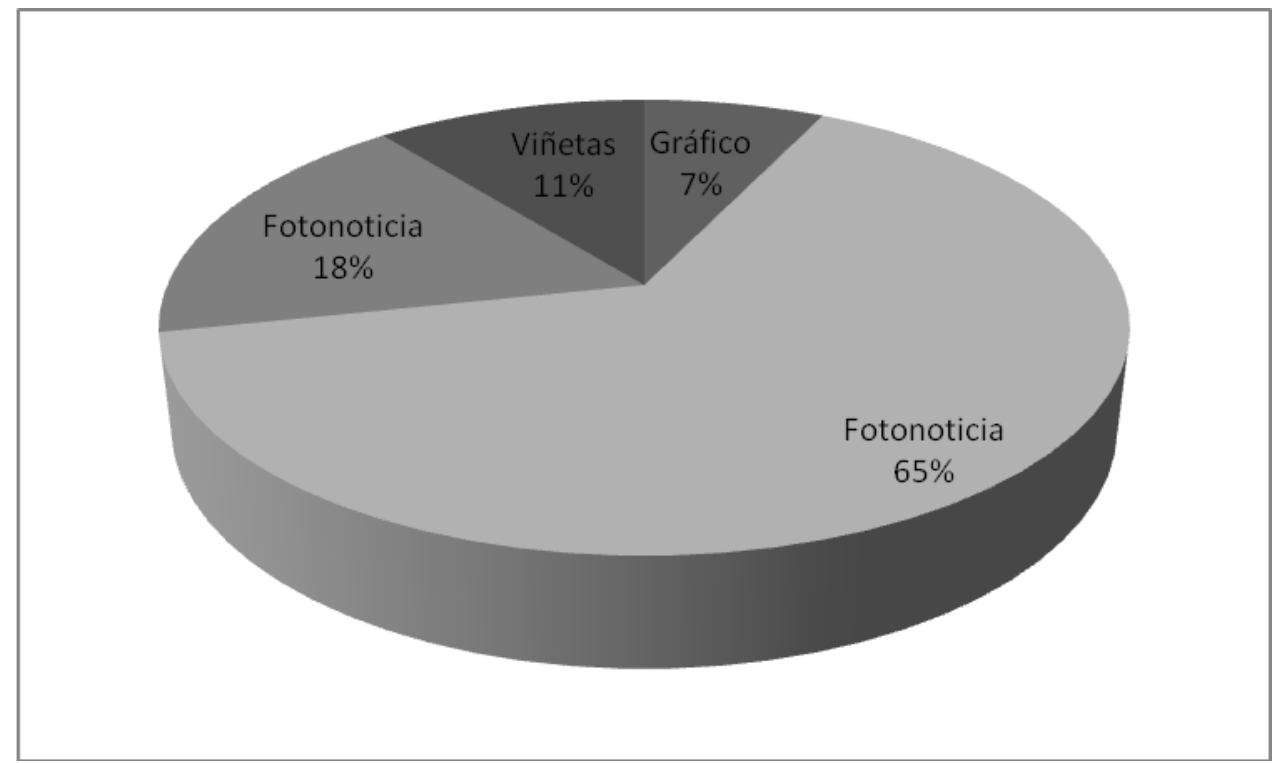

Fuente: Elaboración propia

Gracias al análisis de los ejemplares, podemos señalar que en el 29,1\% (245) de las páginas de los diarios analizados hay algún elemento gráfico relacionado con la Selección, aunque el número y el tipo varía según el diario que analicemos (El País, El Mundo o Abc) y el día en que nos encontremos (12, 13 o 14 de julio de 2010) dato que veremos más detalladamente a continuación. De esta manera, nos encontramos con una media de 27,2 páginas de carácter informativo por ejemplar dedicadas al triunfo de España.

Si prestamos atención a las páginas dedicadas a publicidad encontramos que el $41 \%$ de éstas están dedicadas a anuncios que hacen referencia a la victoria de la Selección o alguno de sus jugadores. Se trata de 57 páginas enteras de publicidad (de un total de 139) en las que alguna marca comercial da la enhorabuena a la Selección o utiliza la imagen de alguno de los futbolistas para promocionar sus productos. Este es el caso de marcas como Visa, McDonald, Mahou o Banco Santander. Vemos así la importancia del acontecimiento y apreciamos cómo las marcas aprovechan este hecho para promocionarse asociando el triunfo de La Roja a su imagen de marca. 
También cabe destacar que el 22,3\% (183) de las páginas de los diarios muestran un cintillo especial. Los diseños escogidos van desde el logotipo del Mundial a la bandera española, pasando por un motivo de la copa de los campeones.

Ya en el diseño de los diarios y en la distribución de las imágenes dentro del periódico se pueden ver diferencias entre las tres cabeceras analizadas. No es necesario entrar en el análisis de contenido para observar que hay criterios diferenciados en el tratamiento que se hace en los periódicos de la victoria de la Selección de Fútbol. El País va a ser el que menos relevancia relativa le dé a la noticia. Esto se puede apreciar, por ejemplo, en el número de páginas en las que aparecen elementos gráficos relacionados con el tema que nos ocupa. En El País suponen un 24,4\% (60) de las páginas analizas, mientras que en El Mundo ascienden a un 41,2\% (101) y en Abc llegan a ser un 34,2\% (84). Además, El País se muestra menos 'patriótico' que los otros dos diarios al no incluir la bandera española en los cintillos, algo que sí recogen El Mundo y Abc.

De la misma forma, si el porcentaje de páginas dedicadas a este tema es menor en El País, es de esperar que también sea el diario que presente menos elementos gráficos relacionados con la Selección. Así, mientras que, en los tres días, El Mundo y Abc cuentan con $171(32,2 \%)$ y $242(45,5 \%)$ elementos gráficos respectivamente, El País se queda solamente con $118(22,2 \%)$.

Gráfico 2: número de elementos gráficos por cabeceras

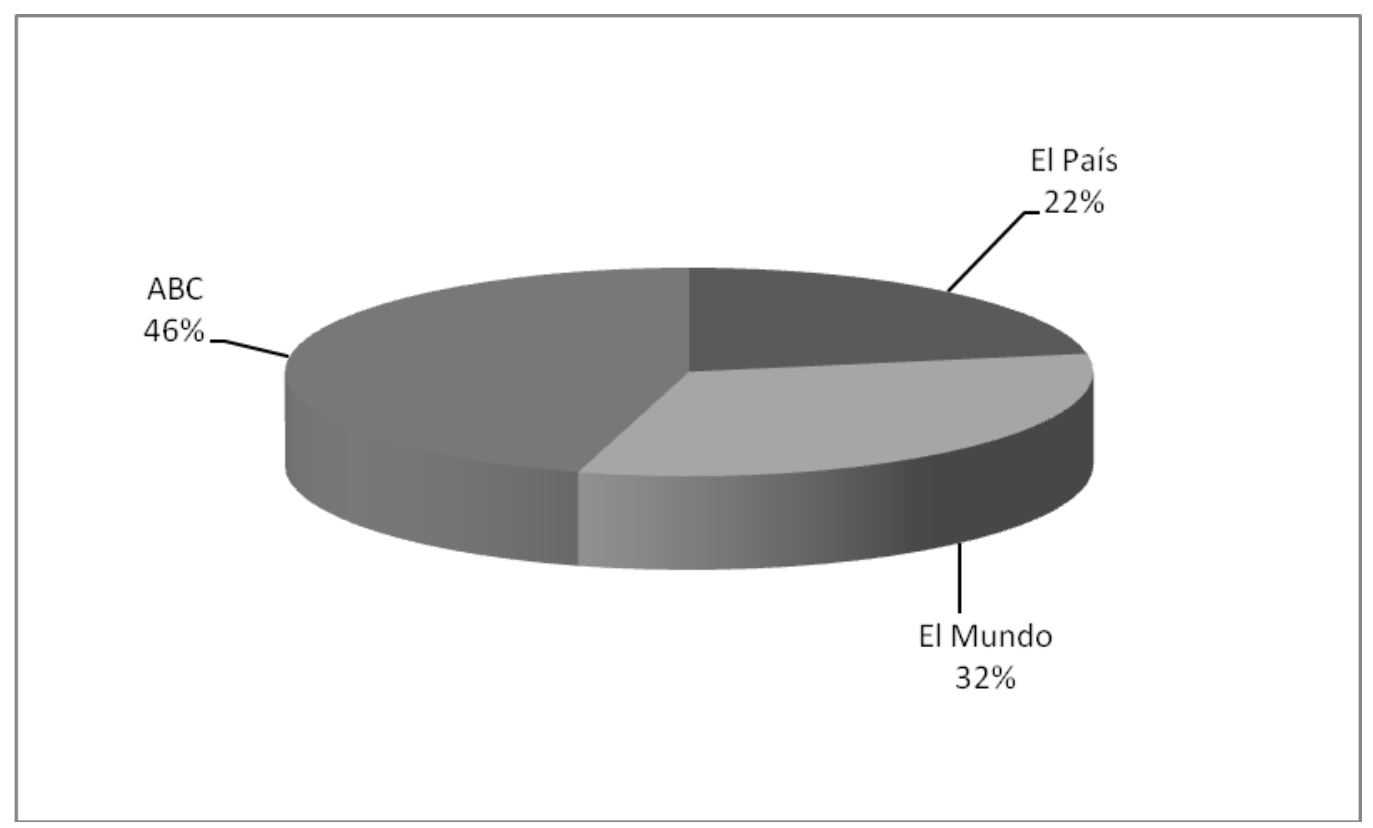

Fuente: Elaboración propia

\subsection{Análisis de los elementos gráficos}

A continuación presentaremos los resultados del análisis de las fotografías y fotonoticias sobre la victoria de la Selección Española de Fútbol encontradas en los nueve ejemplares, las cuales representan el 82,05\% (384) del total de elementos gráficos encontrados. 


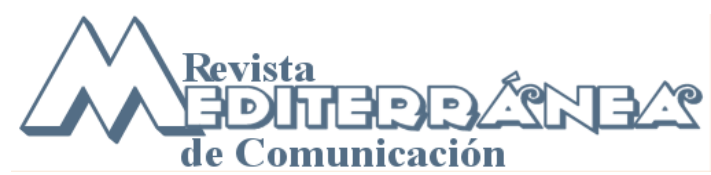

Primero, prestaremos atención a la sección del ejemplar en el que encontramos los elementos gráficos. De esas 384 imágenes, el 46,6\% (179) se encuentran, como es lógico, en las sección de 'Deportes' de los diarios, los cuales presentan una cobertura casi exclusiva al acontecimiento futbolístico. A esto podríamos sumarle el 8,3\% (32) de imágenes del especial 'Sudáfrica 2010' que ofreció El Mundo el 12 de julio y El País el día 13. A continuación, la segunda sección con más número de imágenes es 'Madrid', con el 26,3\% (101) de fotografías, la mayoría centradas en la celebración de los aficionados en las calles del país. Cabe destacar también que encontramos un 9,9\% (38) de imágenes dentro de las secciones de 'Opinión', o, en el caso de Abc, en la de 'Enfoque'. Por último, destacamos que también hay 3,1\% (12) de fotografías en las secciones de 'Información Nacional'. Por tanto, podemos ver como aunque el acontecimiento es recogido mayoritariamente por su sección de origen, 'Deportes', los periódicos también la incluyen en otras secciones menos afines lo que nos demuestra una vez más la importancia del acontecimiento en el país. Esto manifiesta, además, la relevancia del fútbol en España, no ya sólo como deporte de masas, sino asociado a nuestra cultura, en el que como afirma González Ramallal (2004: 281) "Desde que surgió el fútbol en España se trasladó al gran público la idea de la denominada 'furia española' donde el jugador patrio suplía la falta de calidad técnica con un coraje y una raza envidiables que nos distinguía de otras naciones en el terreno de juego".

Respecto a las portada vemos que, como es de suponer, encontramos hasta un $2,3 \%$ (9) de imágenes relacionadas con la Selección ocupando estas páginas. Las imágenes portadas de los tres diarios, Abc, El Mundo y El País, de los días 12 y 13 de julio están protagonizadas por representaciones de la victoria de la Selección. El primer día aparecen imágenes referentes a la Selección posando con la copa y festejando el triunfo en equipo, mientras que el día 13 de pone el acento en la celebración por parte de los aficionados en las calles de la capital. El Mundo, además, mantiene una imagen del entrenador Vicente del Bosque en la portada del 14 de julio.

\subsection{Espacio y tiempo en el que se desarrolla la acción}

Respecto al lugar en el que se desarrollan las 384 fotografías y fotonoticias analizadas, podemos ver que existe cierta relación entre el tipo de escenarios y el día en que aparecen éstos en los periódicos. Así, el día 12 de julio, es decir, el día posterior al partido podemos ver como el 17,9\% (69) de los elementos gráficos seleccionados se localizan en el césped del campo de fútbol en el que se celebró la final. Así, las fotos analizadas tratan el tema del partido y la posterior celebración de los jugadores en el campo, por lo que el único escenario que se muestra en estas fotos es el césped del Soccer City. También debemos de tener en cuenta las fotografías tomadas en el estadio, las cuales representan el 3,9\% (15) de imágenes tomadas el día 12 y que se centraban en representar a la afición que se encontraba en las gradas presenciando la final y a las autoridades asistentes al partido. 
Gráfico 3: escenario en el que se desarrolla la acción

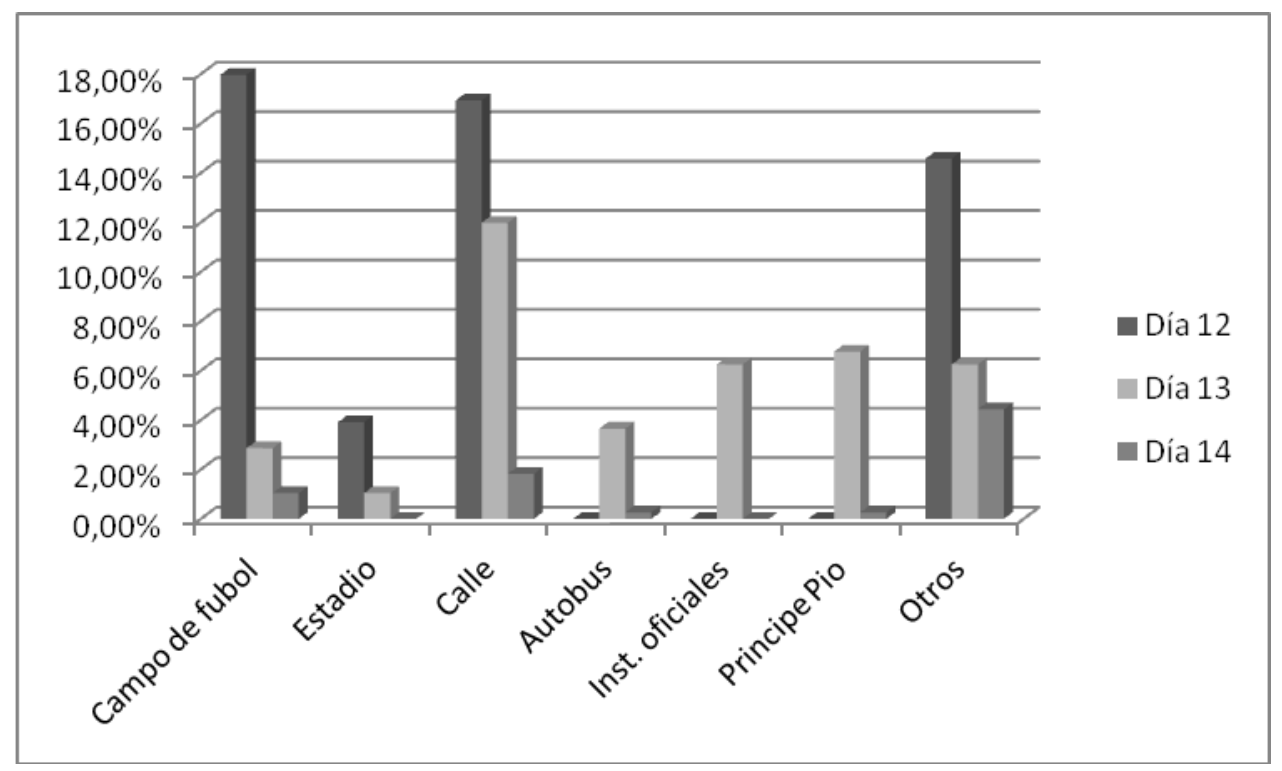

Fuente: Elaboración propia

Por último, también tenemos que prestar atención a las fotografías tomadas en las calles las cuales representan el 16,9\% (65) de las imágenes publicadas el día 12. Éstas hacen referencia a imágenes de personas que tomaron las calles en distintos puntos de España la misma noche en que la Selección ganó la final.

Respecto a las imágenes publicadas el día 13 de julio llaman la atención tres escenarios: las calles, el escenario de Príncipe Pío en el que se celebró la victoria con toda la afición y las instituciones oficiales donde fueron recibidos los futbolistas. Así, los elementos gráficos referidos a las calles representarían el $11,9 \%$ (46) de las imágenes de ese día. Aquí los protagonistas fueron los aficionados, que como analizaremos más adelante, son representados como una marea humana. A continuación destacaría el escenario de Príncipe Pío con un total del 6,6\% (25) de las imágenes y en las que se conjugarían fotografías de la afición que se congregó allí, de los jugadores de la Selección y de los invitados que actuaron en la gala celebrada. Por último, encontramos las fotografías dentro de las instituciones oficiales donde fueron recibidos los jugadores, entre ellos el Palacio de la Zarzuela en las que los jugadores aparecen fotografiados con distintos miembros de la Casa Real como son los Reyes, los Príncipes de Asturias o las Infantas Leonor y Sofía o La Moncloa en la que fueron recibidos por el Presidente del Gobierno.

Del día 14, debemos señalar que las imágenes que aparecieron en los periódicos no se centraron en ningún escenario en especial y en ella se recogían imágenes de jugadores, aficionados o personajes públicos en los que se hacia alguna referencia a la victoria de La Roja. Solamente aparecieron algunas fotografías que podemos localizar en el estadio donde se jugó la final - 1,0\% (4) - y otras en las calles de la capital - 1,8\% (7) - . El acontecimiento pierde la fuerza con la que entró en los medios los dos días anteriores y se limita a recoger únicamente los momentos más importantes de la victoria de la Selección. 


\subsection{Análisis cualitativo}

Encontramos un 20\% (77) fotografías que muestran a la Selección Española de Fútbol celebrando su propio triunfo. Los jugadores y el equipo técnico son los protagonistas de estas imágenes.

Dentro de las imágenes que recogen la celebración de la Selección, como protagonistas únicos, encontramos dos tipos de fotografías. Por un lado, las imágenes de grupo, en las que aparecen todos o casi todos los jugadores y el equipo técnico celebrando el triunfo por todo lo alto, que suelen encuadrarse en planos largos generales. Por otro, las fotografías en las que hay un único protagonista o un número reducido, en las que se suele mostrar a los jugadores más emocionados encuadrados en planos más cortos, como el plano medio o el primer plano.

En las primeras encontramos imágenes muy expresivas, en las que los jugadores no tienen reparos en mostrar su alegría tras haber conseguido ganar el mundial. Se les ve, en muchas ocasiones, con los brazos en alto y los puños cerrados, en señal de victoria y de celebración en un tono eufórico. A pesar de haber hecho un análisis de medios impresos, las imágenes transmiten la sensación de poder escuchar los sonidos de celebración y alegría del momento, ya que se nota que los jugadores están gritando al aparecer con la boca abierta en muchas ocasiones y formar un grupo grande de personas, que a su vez están rodeados de un estadio o calles repletas de aficionados.

Tras la victoria, todo vale. Se ve a los jugadores en actitud gamberra y desenfadada. No guardan las formas; visten complementos algo ridículos, como grandes sombreros 0 trompetas; y tienen reacciones de exaltación.

Se presenta a los jugadores como grandes vencedores, laureados por su triunfo; un triunfo que ha costado conseguir y que merece una celebración por todo lo alto. Esto se ve en el gran número de personas que les acompaña en las diferentes celebraciones, así como en los recursos desplegados, como los fuegos artificiales o la suelta de papeles de colores, que cobran importancia y adornan muchas imágenes. También llaman la atención las medallas que cuelgan del cuello y que en ocasiones los jugadores muerden o besan. La cinta azul de la medalla resalta sobre la equipación de color rojo que visten, dejando muy claro quiénes han sido los ganadores de la competición.

También cobra importancia la figura del entrenador Vicente del Bosque, que suele aparecer en el centro de las imágenes, arropado por sus jugadores, que suelen mirar hacia él. Reconocen en él una figura de autoridad clave para la consecución de la victoria.

Un hecho que se aprecia con claridad en las fotografías es la cohesión de grupo. Se muestra a los jugadores haciéndose compañía, realizando las mismas actividades a la vez, alegrándose por un logro conseguido en equipo.

Esto se ve también en las imágenes en las que aparecen pocos jugadores, en las que se les muestra abrazándose, mostrando agradecimiento y comprensión los unos a los otros.

En cuanto a las imágenes tomadas durante el partido en las que el protagonista es un sólo jugador todas destaca la representación de su lado sobrehumano. Se intentó captar el 
césped como un campo de batalla en el que ambos equipos lucharon como auténticos guerreros para lograr la victoria.

Algunas de las imágenes más significativas son las relacionadas con el capitán de la Selección, Iker Casillas, el cual, por ejemplo, en una imagen publicada en Abc del día 12, aparece prácticamente volando sobre el resto de adversarios para atrapar el balón al que acaricia con sus dedos.

También destaca el momento en el que Iniesta mete el gol de la victoria para España. En la página 48 de El País del 12 de julio se ve en un plano entero al jugador de La Roja chutando a puerta, mientras el portero y un defensa de la Selección holandesa miran aterrados al jugador prediciendo lo que iba a suceder. Se muestra, además, la grandeza de nuestro jugador frente a la debilidad del otro equipo, ya que como revela la imagen, incluso frente a dos jugadores, Iniesta, es capaz de batir la portería rival.

Posterior a este instante, otro momento destacable y representando en los periódicos es la celebración del gol de Iniesta. Esta imagen apareció en los tres periódicos analizados y en ella se muestra un primer plano del jugador con los brazos en cruz y una camiseta en la que se leía una frase en recuerdo a su amigo fallecido Dani Jarque. Esta foto de Iniesta es la imagen del héroe ya que simbolizó el fruto de la lucha y el trabajo. En segundo plano, se muestra de nuevo a una Selección holandesa derrotada y desesperada, con las manos en la cabeza.

Las fotos de los jugadores, una vez concluido el partido, siguen siendo muy representativas. En éstas se ve una mezcla de emociones por lo conseguido, en las que se alterna el llanto por la lucha y la alegría por la victoria. Es decir, se puede ver en los rostros de los jugadores la satisfacción al ser conscientes de lo que han logrado y lo que han luchado para ello. Se les suele mostrar en soledad, como si buscaran un momento para afrontar el momento que están viviendo. Se les nota agradecidos y orgullosos por lo que han conseguido, a la vez que incrédulos. Se aprecia entonces, en las imágenes posteriores al partido una coherencia secuencial similar a los vencedores de una batalla histórica: la lucha y sus penurias, la victoria, la asimilación del logro y la celebración.

Estas fotos siguen representando la dicotomía entre vencedores y vencidos, por lo que es normal encontrar imágenes en las que algún jugador celebra la victoria, mientras que en un segundo plano aparecen jugadores holandeses derrotados en el suelo llevándose las manos a la cabeza.

Una vez entregada la copa, las fotos más significativas vienen de la mano del capitán del equipo, Iker Casillas que aparece en numerosas instantáneas besando la copa del Mundo. Casillas, se muestra en las imágenes como el más sobrio frente a sus compañeros, que no dudan en saltarse el protocolo improvisando cada acto de la celebración: se abrazan, bailan o jalean a la afición. Otra imagen emotiva del momento posterior al partido es cuando Villa, en un primer plano, con la Copa en una mano y la bandera de España en la otra hace un gesto en señal de ofrenda a la grada, que aparece ocupando todo el fondo de la foto, dando a entender que todo esto que han conseguido es de todos los españoles.

De las $17,4 \%$ (67) fotografías en las que la Selección está acompañada, en 32,8\% (22) casos aparecen personalidades públicas que participan en las celebraciones del triunfo. 
En la mayoría de estas imágenes quienes acompañan a los jugadores son miembros de la Casa Real 17,91\% (12). El día de la victoria, en el estadio de fútbol, se muestra a la Reina Doña Sofía orgullosa de los jugadores, en una actitud muy maternal. Es el caso de la imagen publicada en el diario Abc del12 de julio en la página 10.

Salieron muchas imágenes de los jugadores y otras personalidades tras el encuentro, en salas privadas del estadio. Estas imágenes denotan un ambiente festivo e informal, donde los miembros de la Casa Real dejaron de lado el protocolo y entraron en contacto directo con los jugadores. Se aprecia que quieren formar parte de la celebración y que quede constancia de ellos con la toma de fotografías. Muestra de ello es una imagen que se repite en las tres cabeceras en la que aparecen Iker Casillas, Rafael Nadal y la Reina Doña Sofía. En esta instantánea se ve a los tres orgullosos del triunfo de España y se muestra una representación de cada uno de los personajes como iguales, es decir, no hay distinción entre Nadal o Casillas con la Reina, ya que los tres son seguidores de La Roja y no quieren perder la oportunidad de retratar ese instante de euforia vivido.

El 12 de julio la Selección Española acudió al Palacio Real como parte del recorrido de la celebración. En una recepción como ésta también hubo momentos para saltarse el protocolo, en primer lugar, permitiendo que las Infantas Leonor y Sofía acudan a dicha recepción y, además, vestidas con camisetas de la Selección, y que jugaran con la copa, que se la ofrece el capitán, Iker Casillas.

En este encuentro, se realiza lo que llamaríamos 'fotografía de familia', en la que impera la sobriedad que contrasta con el ambiente festivo de las imágenes descritas hasta el momento. La colocación de los asistentes es muy protocolaria. En el centro y en primera fila encontramos a diferentes miembros de las Casa Real junto al entrenador y al capitán del equipo, rodeados por los jugadores. En las últimas filas se colocan otras personalidades del deporte. Se trata de una imagen en la que, salvo por la presencia de las Infantas, el protocolo está muy cuidado. Esto se nota también en la vestimenta de las personas fotografiadas, que van de traje oscuro o con la equipación deportiva elegida para este día. Predominan por tanto el negro y el rojo, destacando éste último en la indumentaria de los jugadores y de la Reina.

El mismo día, los jugadores también acudieron al Palacio de la Moncloa a celebrar el triunfo con el presidente José Luis Rodríguez Zapatero, quien puso más reparo en saltarse el protocolo. En el momento en el que lo hizo, saltando y portando la copa, aparece más bien ridiculizado. Además, a este encuentro acudió el hijo del entrenador Vicente del Bosque, un joven con síndrome de Down que eclipsó la presencia de Rodríguez Zapatero. Se le integró en la celebración como si fuera uno más del equipo.

Otra instantánea que apareció en las tres cabeceras fue el momento en el que la periodista Sara Carbonero entrevista al capitán de la Selección y, de forma espontánea, éste besa a la periodista, su pareja en la vida privada, como muestra de agradecimiento por el apoyo que le había prestado durante toda la competición. La euforia del momento muestra de nuevo facetas desconocidas de los jugadores, ya que aunque ya era conocida la relación de la pareja, ésta nunca traspasó los límites de lo privado. Fue un gesto que todo el mundo realmente estaba esperando y así lo recogieron los periódicos, los cuales daban relevancia al hecho llenándolo de emoción por parte de sus protagonistas. De nuevo, era un día en el que todo estaba permitido. 
Respecto a la representación de los aficionados en la victoria de la Selección Española encontramos $28,9 \%$ (111) fotografías.

En la mayoría de los casos, se representa a los aficionados como una marea humana. Para ello, se usaron fotografías de planos generales obtenidas con gran angular en las que primaba el formato horizontal. Gracias a estas imágenes, se aprecia una especie de cosificación en la figura de los personajes focalizados, los cuales ya no son vistos de forma individual sino como una gran masa que se mueve de forma conjunta. De esta manera se intenta representar la gran repercusión que tuvo en nuestro país la victoria de España, potenciando el dinamismo de la masa echándose a la calle.

En este sentido hay dos elementos que cobran especial protagonismo en las fotos de la hinchada roja: por un lado, el propio color rojo, el cual se convierte en una seña de identidad de todos los que están festejando el triunfo en la calle, bien a través de las banderas que portaban, camisetas de la Selección u otros elementos rojos a modo de identificación con la Selección Española. Por otro, los símbolos nacionales usados para la celebración. Es normal ver en las fotografías imágenes panorámicas de la marea que inundó las calles de la capital y, como telón de fondo, monumentos emblemáticos de la capital de nuestro país, como La Puerta de Alcalá o El Oso y el Madroño. Hablamos, por tanto, de fotografías con referentes claramente identificables por los lectores, lo que facilita la comprensión y lectura de las imágenes.

Si antes destacábamos las fotos de los aficionados como marea humana, también debemos subrayar los planos cortos en los que se muestran pequeñas pinceladas de lo que fue la celebración por parte de la hinchada. En estas fotografías se intenta captar lo genuino de la afición roja en un día en el que todo estaba permitido. Podemos ver personas tirando agua desde un balcón, debido a las altas temperaturas de esos días, gente con la cara totalmente pintada de los colores de la Selección o disfrazada de personajes tan simbólicos en España como son los toreros y las sevillanas.

Aun así, lo más destacable, son los planos medios de la afición en la que se pueden intuir la emoción del momento: gente con los brazos en alto en señal de victoria, abrazos y lloros como representación de la alegría y sorpresa por el triunfo o caras desencajadas de gente gritando que nos permiten 'oir' los cantos de la victoria. Fueron días en los que todos estábamos en la calle festejando algo que sentíamos como nuestro, como propio.

Otro elemento de gran importancia que apareció en estas fotografías es la bandera, ya no sólo como elemento protagonista en referencia al color, sino como elemento que daba movimiento a las fotos, ya que en ellas se mostraba la bandera ondeada por los protagonistas de las imágenes a modo de símbolo de victoria nacional. Al igual que ocurría en las instantáneas que reflejaban la marea humana, la bandera también se capta en movimiento alejándola de la idea de estaticidad.

En 77,08\% (296) fotografías aparece la bandera representada de alguna forma. Encontramos 39,1\% (150) imágenes en las que aparecen banderas de tela ondeadas por diferentes personas o colocadas en ventanas o balcones. Además, hay $70,1 \%$ (296) fotografías en las que la bandera se encuentra en el vestuario de la gente, y en 13,8\% (53) casos aparece pintada en la piel de los personajes, como es la imagen publicada en la página 20 de El País del 13 de julio de 2010, en la que un joven de raza negra posa con la bandera de España dentro del contorno del continente africano pintada en el rostro. Se trata 


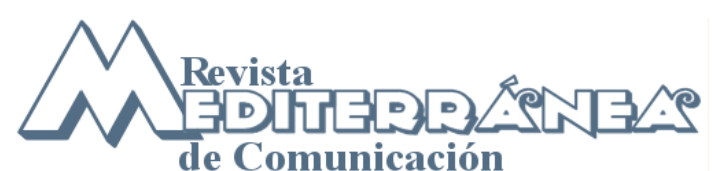

de fórmulas de identificación simbólica con mucho potencial. Vestir cierto símbolo o pintarlo en el rostro denota que el sujeto le otorga mucha importancia y significado respecto a su identidad.

Podemos decir que la connotación más negativa que tiene la bandera española, relacionada con el franquismo, va perdiendo peso a causa de encuentros deportivos como éste, donde el sentimiento de victoria se posiciona por encima de las ideologías políticas.

Gráfico 4: aparición de la bandera española

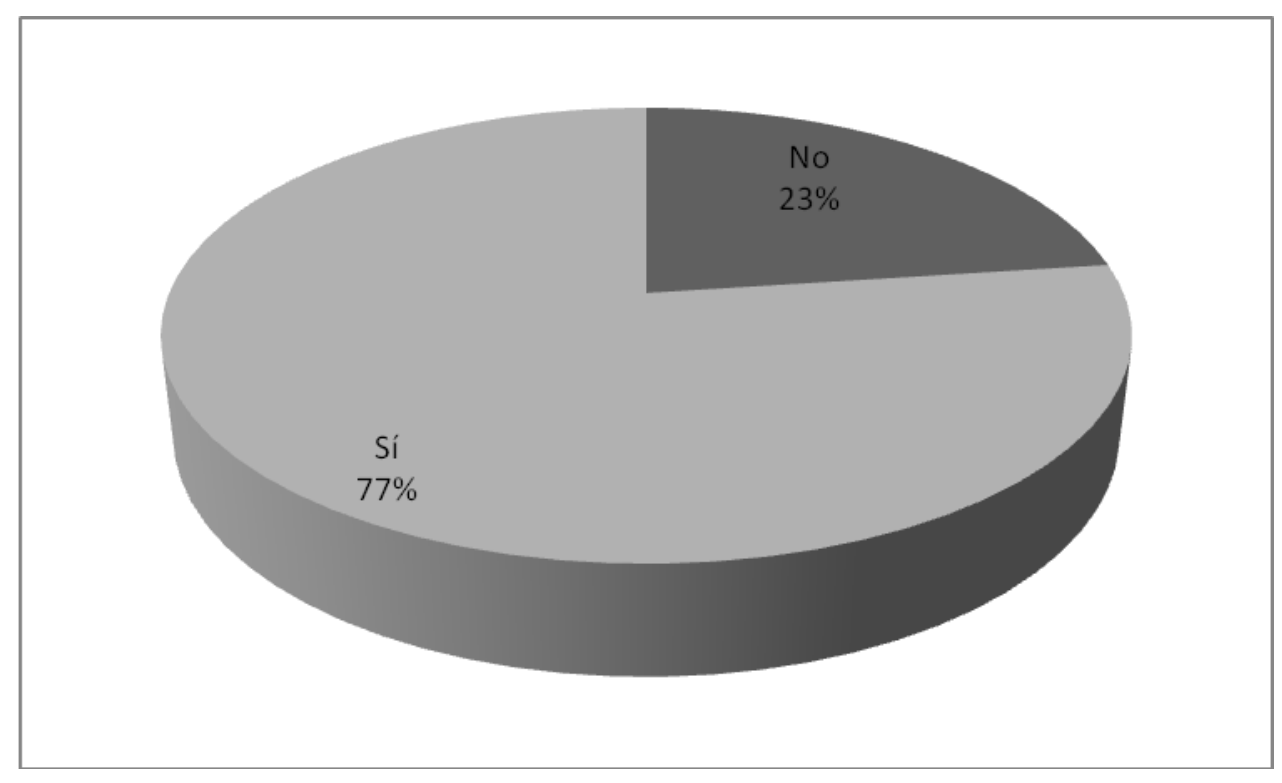

Fuente: Elaboración propia

La copa del Mundial de Sudáfrica 2010 fue también protagonista en la celebración de la victoria de España. Ésta parece en 14,30\% (55) fotografías.

Destaca, por ejemplo, su imagen en un primer plano, en la foto publicada en 13 de julio en El País, sostenida por uno de los jugadores de la Selección de quien sólo vemos sus manos y que la rodean por una bandera de nuestro país. Luce así, sin ningún adorno ya que su sola presencia representa la grandeza de la victoria.

En otras imágenes aparece, también, de la mano de muchos de los jugadores de la Selección que no dudan en besarla como señal de posesión del trofeo, este sería el caso del capital, Iker Casillas, que aparece en numerosas imágenes haciendo este gesto.

Pero la copa también es protagonista de otras imágenes en las que ocupa el lugar de un miembro más de la celebración. La vemos así en numerosas instantáneas con diversos personajes públicos, desde miembros de la Realeza - los Príncipes de Asturias, el Rey, las Infantas Leonor y Sofía- hasta el Presidente del Gobierno. Todo el mundo quiere posar con ella.

Por último, hay que subrayar que aparecen fotografías en las que destaca un juego de planos entre la copa y el resto de protagonistas de la foto. Por ejemplo, en la recepción del Presidente del Gobierno a los jugadores de la selección se muestra una fotografía en la que 


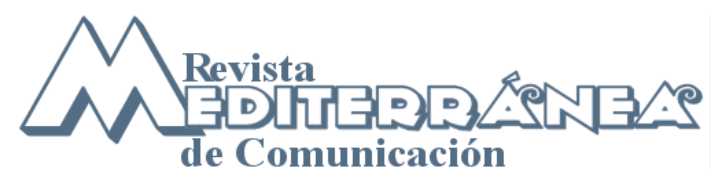

ISSN 1989-872X - Año3 (2012), pp. 59-78

Rodríguez Zapatero está felicitando a los jugadores y en la derecha de la imagen se muestra la copa, que aunque desenfocada, simboliza la presencia de la victoria. Es decir, es necesario sacar una foto institucional del Presidente felicitando a los jugadores, pero sin olvidar que la copa y la victoria están presentes.

Hace no tanto tiempo exhibir los colores de la bandera española no estaba bien visto para según qué personas. La bandera tiene unas connotaciones políticas que a lo largo de los años se han ido difuminando, entre otros factores, a causa de los triunfos de deportistas españoles. Esta situación ha llegado a su máxima expresión con la victoria de la Selección Española en el Mundial de Fútbol de Sudáfrica en 2010.

No sólo las personas se han atrevido a vestir con los colores nacionales y a sacar las banderas por la ventana, sino que los medios de comunicación han aprovechado la nueva situación. En concreto, la prensa ha hecho un tratamiento visual bastante espectacular y basado en los colores de la bandera.

La victoria española ha contado con un grandísimo seguimiento mediático donde la bandera y el color rojo son los protagonistas. La prensa ha mostrado los símbolos nacionales sin tapujos, si bien esta expresión ha sido mayor en periódicos como El Mundo o Abc, mientras que El País se ha mostrado algo más moderado.

Los vencedores, el equipo de fútbol, han sido protagonistas en una gran cantidad de imágenes, como es natural. Sin embargo, casi ha resultado más noticioso la gran celebración de la ciudadanía, ya que son los aficionados los que se han convertido en protagonistas de muchas fotografías. La hinchada se ha mostrado como el soporte idóneo para exponer los colores y la emoción del momento. Así lo señalaba también González Ramallal (2008: 281), que afirmaba que "los aficionados configuran el soporte humano y emocional, componente fundamental del fenómeno futbolístico. Además de con la propia España, que les representa, los aficionados protagonistas en los medios, constituyen el elemento más próximo al lector, con el cual éste se siente más identificado".

En definitiva, la consecución del Mundial de Fútbol de 2010 ha sido un hecho histórico que ha marcado el diseño visual de los periódicos.

\section{Conclusiones}

En las últimas décadas, exhibir los colores de la bandera española no estaba bien visto en algunos contextos, debido a que la bandera podía tener connotaciones políticas negativas. A lo largo de los años, esta situación ha ido cambiando y se ha ido disipando, entre otros factores, a causa de los triunfos de deportistas españoles, en especial con los logros del deporte más seguido del país, el fútbol, como ya ocurrió con la consecución de la Eurocopa de 2008.

No sólo las personas se han atrevido a vestir con los colores nacionales y a sacar las banderas por la ventana, sino que los medios de comunicación han aprovechado este hecho. En concreto, la prensa ha realizado un tratamiento visual exclusivo para estos días, bastante espectacular y basado en los colores de la bandera. La victoria española ha contado con un gran seguimiento mediático donde la bandera y el color rojo son los protagonistas. La prensa ha mostrado los símbolos nacionales sin tapujos, si bien esta expresión ha sido mayor en periódicos como El Mundo y Abc, mientras que El País se ha mostrado algo más moderado. 


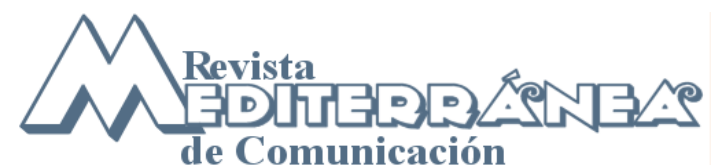

ISSN 1989-872X - Año3 (2012), pp. 59-78

Además del protagonismo del color rojo y de la bandera, la copa también ha ocupado un papel importante y central en muchas imágenes, al ser la expresión máxima del triunfo.

Se han mostrado las capacidades más físicas de los futbolistas de la Selección Española, representándoles como guerreros durante el partido, dejando su lado más emocional para las imágenes tomadas en los momentos y días sucesivos. La victoria les dio carta blanca para actuar sin límites en la celebración, mostrando abiertamente su euforia.

De este sentimiento de victoria todos quisieron formar parte, tanto personajes públicos, cobrando gran relevancia los miembros de la Familia Real, como aficionados de todo tipo, que ocuparon las calles para celebrar un hecho deportivo histórico.

\section{Bibliografía}

Abreu, C. (2004): "El análisis cualitativo de la foto de prensa" en Revista Latina de Comunicación Social, número 57, enero- junio. En la URL: http://www.ull.es/publicaciones/latina/20040757abreu.htm consultado el 10 de septiembre de 2011.

Alonso Erausquin, M. (1995): Fotoperiodismo: formas y códigos. Madrid: Síntesis.

Aparici, R. y García Matilla, A. (1998): Lectura de imágenes. Madrid: La Torre.

Baeza, P. (2001): Por una función crítica de la fotografía de prensa. Barcelona: Gustavo Gili.

Barthes, R. (1990): Lo obvio y lo obtuso. Río de Janeiro: Nov Fronteira.

Berrocal, S. y Rodríguez, C. (1998): Análisis básico de la prensa diaria. Manual para aprender a leer un periódico. Madrid: ed. Universitas.

Castañon, M.R. Y J. Castañon (2006): "Cambios en la redacción periodística del deporte en América y España en el siglo XXI" en Revista Digital Universitaria, numero 6, vol 7. En la URL: http://www.revista.unam.mx/vol.7/num6/art50/jun_art50.pdf consultado el 12 de septiembre de 2011.

Dunning, E. (1992): "La dinámica del deporte moderno: Notas sobre la búsqueda de triunfos y la importancia social del deporte" en ELIAS, N. \& DUNNING, E. Deporte y ocio en el proceso de la civilización. Madrid: Fondo de cultura económica.

Esteve, F. y Fernández del Moral, J. (1998): Áreas de especialización periodística. Madrid: Fragua.

García Maza, M.C. (2005): "Situación actual del fotoperiodismo". Espacios públicos, febrero, año7, vol. 8, número 015, Universidad Autónoma del Estado de México, pp. 262-276. En la URL: http://redalyc.uaemex.mx/pdf/676/67681518.pdf consultado en: 20 de septiembre de 2011.

Gonzalez Ramallal, M.E. (2004): Sociedad y deporte: análisis del deporte en la sociedad y su reflejo en los medios de comunicación en España. Tesis doctoral presentada en el departamento de Sociología y Ciencia Política y de la Administración de la Universidad de la Coruña. 
Igartua, J.J. y Humanes, M.L. (2004): Teoría e investigación en comunicación social. Madrid: Síntesis.

Paniagua Santamaría, P. (2010): "Información deportiva, la especialización más extendida". En Camacho Markina, C. La especialización en el periodismo. Formarse para informar. Sevilla: Comunicación social ed.

Rodríguez Merchán, E. (1993): La realidad fragmentada. Madrid: Editorial de la universidad Complutense.

Texeira Ribeiro, L.A. (1998): "Cámara abierta. Estudio de caso sobre el papel del fotoperiodista". Revista Latina de Comunicación Social, número 9. En la URL: http://www.ull.es/publicaciones/latina/a/39tei.htm consultado en: 20 de septiembre de 2011.

Torregrosa, J.F. (2009): La fotografía de prensa. Una propuesta informativa y documental. Madrid: Dykinson.

Vilches, L. (1993): Teoría de la imagen periodística. Barcelona: Paidós.

Villafañe, J. (1985): Introducción a la teoría de la imagen. Madrid: Pirámide.

Wimmer, R. y Dominick, J.R. (1996): La investigación científica de los medios de comunicación. Una introducción a sus métodos. Barcelona: Bosch. 